\title{
Evaluation of Applicability for Ni-advanced Weathering Steels and Bridge High-performance Steels to Railway Steel Bridges
}

\author{
Ichiro SUGIMOTO, Dr. Eng. \\ Senior Researcher, \\ Laboratory Head, \\ Steel \& Hybrid Structures Laboratory, Structures Technology Division
}

\begin{abstract}
The design standard for railway steel structures and composite girders was recently revised, and its range of applicability was extended to recently developed steel materials including Ni-advanced weathering steels and Bridge High-performance Steels (BHS). Niadvanced weathering steels can be applied without painting to bridges in corrosive environments, while BHS materials feature high strength and enhanced weldability. This paper explains the method of evaluation for the applicability of Ni-advanced weathering steels from the results of exposure tests, and outlines the advantages of BHS application to railway bridges from the results of trial design.
\end{abstract}

Keywords: Ni-advanced weathering steel, exposure test, applicability evaluation, Bridge High-performance Steel, trial design

\section{Introduction}

When designing structures, it is important to establish a broad view of structural planning from fabrication to the maintenance of the structures to be constructed. It is advantageous to reduce overheads at each stage, including fabrication costs, material costs (amount of steel) and maintenance costs. The application of recently developed new materials can be considered as a measure for cost reduction.

The design standard for railway steel and composite structures was revised in 2009 [1]. On the occasion of the revision, we investigated the applicability of new steel materials to railway bridges. We focused on nickel-advanced weathering steels and Bridge High-performance Steels (BHS), selected as representative steel materials with application experience and high demands. Ni-advanced weathering steels have a higher level of corrosion resistance than JIS weathering steels, and can help to reduce maintenance costs. BHS have high strength and enhanced weldability, and can help to reduce material costs and fabrication costs.

This paper firstly explains the method of applicability evaluation for $\mathrm{Ni}$-advanced weathering steel. It also outlines the advantages of applying BHS to railway bridges from the results of trial design.

\section{Evaluation of applicability for Ni-advanced weathering steels}

\subsection{Weathering steels and the existing method of applicability evaluation}

Weathering steel forms a protective rust layer on its surface, which prevents the steel from corroding. Accordingly, such steels can be applied to structures without the need for painting. Unpainted bridges do not require repainting, meaning that maintenance costs can be reduced.
Conventional weathering steels, known as "JIS weathering steels" [2], have been applied to many structures. However, in severely corrosive environments, flaking of the rust layer occurs and a protective layer cannot be formed. For this reason, the area of applicability for unpainted weathering steel is limited depending on the distance from the coastline and the amount of airborne salt [3], as shown in Fig. 1 and Table 1.

Ni-advanced weathering steels were developed to extend the area of applicability to more severely corrosive environments in which JIS weathering steels cannot be applied. These steels contain mainly nickel, and other alloy components vary according to the type of steel [4], as shown in Table 2. An example of a railway bridge on which Niadvanced weathering steel was applied is shown in Fig. 2. This bridge is located in a coastal area (Area I in Fig. 1).

In the existing method of applicability evaluation, the advantages of Ni-advanced steel cannot be taken into account. In addition, the existing method cannot evalu-

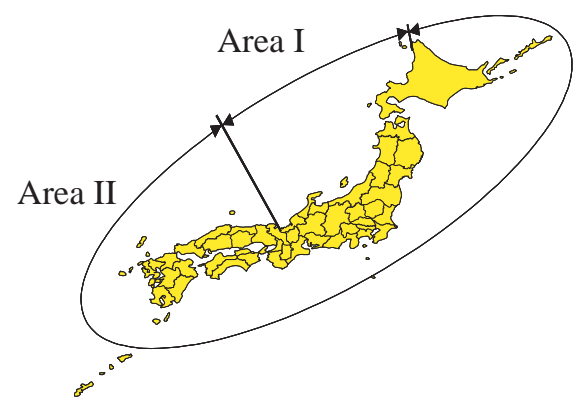

Fig. 1 Area for evaluation of applicability

Table 1 Applicable limits of weathering steels

\begin{tabular}{|c|c|c|}
\hline Area & Distance from coast & Airborne salt \\
\hline \multirow{2}{*}{ Area I } & $0-20 \mathrm{~km}$ & $0-0.05 \mathrm{mdd}$ \\
\cline { 2 - 3 } & $20 \mathrm{~km}-$ & (exempted) \\
\hline \multirow{2}{*}{ Area II } & $0-10 \mathrm{~km}$ & $0-0.05 \mathrm{mdd}$ \\
\cline { 2 - 3 } & $10 \mathrm{~km}-$ & (exempted) \\
\hline
\end{tabular}


Table 2 Ni-advanced weathering steels

\begin{tabular}{|c|l|}
\hline Material & \multicolumn{1}{|c|}{ Components } \\
\hline & $3.0 \% \mathrm{Ni}-\mathrm{Cu}$ \\
& $2.7 \% \mathrm{Ni}-\mathrm{Cu}-\mathrm{Ti}$ \\
Ni-advanced weathering steel & $2.5 \% \mathrm{Ni}-\mathrm{low}$ carbon \\
& $1.5 \% \mathrm{Ni}-\mathrm{Mo}$ \\
& $1.2 \% \mathrm{Ni}-\mathrm{Cu}$ \\
& $1.0 \% \mathrm{Ni}-\mathrm{Cu}-\mathrm{Ti}$ \\
\hline JIS Weathering steel & $0.3 \% \mathrm{Cu}-0.5 \% \mathrm{Cr}$ \\
\hline
\end{tabular}

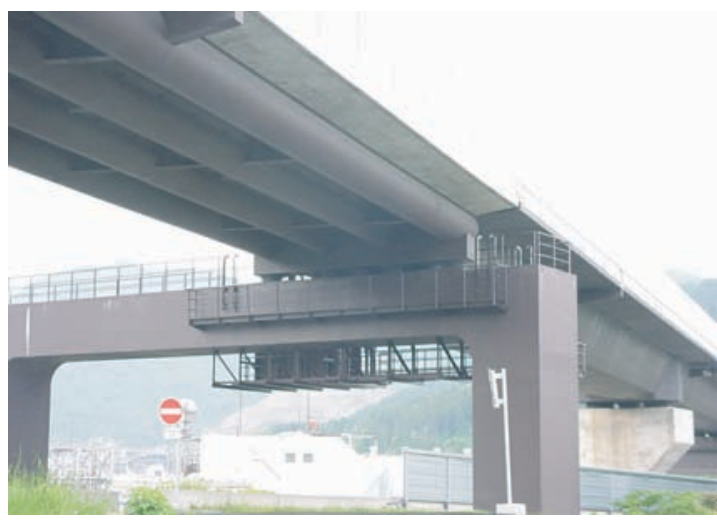

(Photograph by JRTT and Nippon Steel Corp.)

Fig. 2 Hokurikudo Overbridge on the Hokuriku Shinkansen line

ate corrosion factors related to the environment other than airborne salt. Thus, it is necessary to execute evaluation using a new method.

\subsection{New method of applicability evaluation}

To evaluate the applicability of weathering steels including the $\mathrm{Ni}$-advanced type, Miki et al. proposed a new method using exposure test and prediction of long-term corrosion loss [4].

In the exposure test, steel specimens are exposed at a construction site for a year, and the specimen weight loss is measured. This weight loss is then recalculated to give an average decrease in thickness, which is defined as the corrosion loss. Based on the corrosion loss, the longterm corrosion loss for each steel type can be calculated using the following equation:

$$
Y=A \cdot X^{B}
$$

where Y: corrosion loss (mm), X: period of exposure (years), A: parameter for the corrosiveness of the local environment, and $\mathrm{B}$ : parameter for the protective layer. $\mathrm{Pa}-$ rameter $\mathrm{A}$ is equivalent to the corrosion loss in the first year $(X=1)$. Parameter $B$ represents the degree of corrosion speed decrease due to the protective rust layer formed on the surface of the steel. These parameters can be calculated according to the components of each steel type [4].

The applicability of weathering steels is evaluated by comparing the predicted corrosion loss with the requirement for corrosion loss according to the level of anti-corrosion design [5], e.g., less than $0.5 \mathrm{~mm}$ per 100 years.

\subsection{Exposure test}

To verify the effectiveness of the new evaluation method, we carried out an exposure test on weathering steels at a bridge located about $60 \mathrm{~m}$ from the coast. Figure 3 shows the bridge at the test site and the results of airborne salt measurement. The test site is located in a severely corrosive environment characterized by strong sea winds. According to the existing evaluation method (Table 1), the amount of airborne salt exceeds the applicable limit in all parts of the test site. The specimens were placed at four surfaces on each beam of the trestle pier, as shown in Fig. 4, and were exposed for periods of one, three and five years.

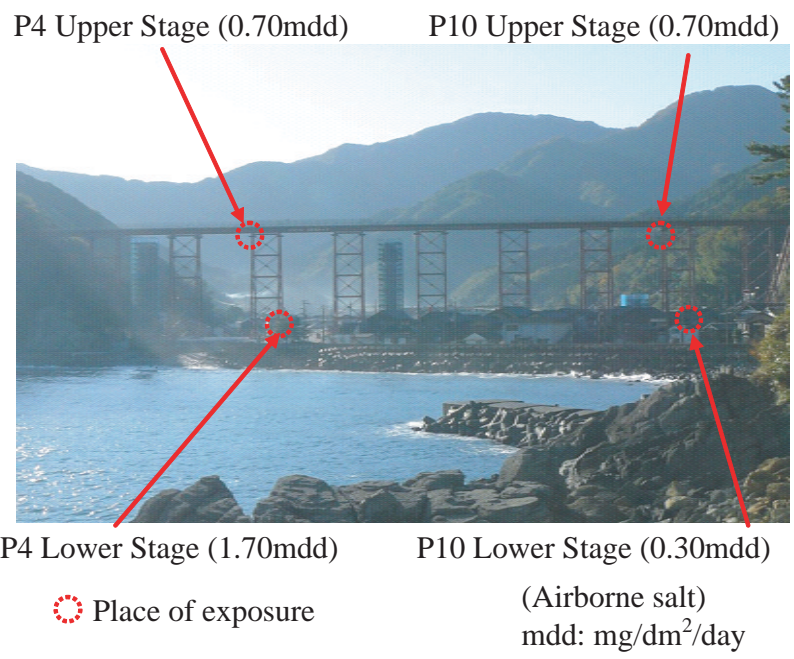

Fig. 3 Exposure test site and measured airborne salt

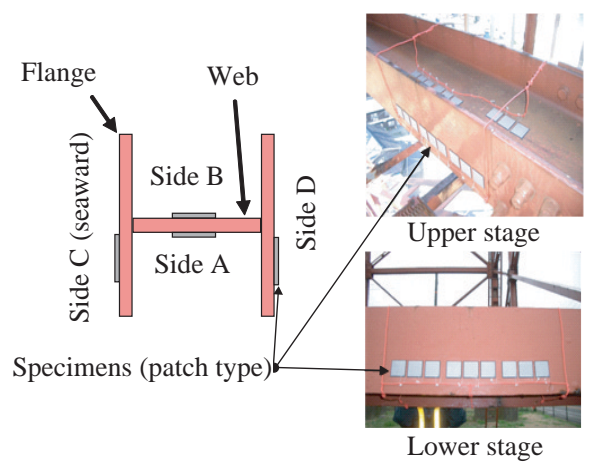

Fig. 4 Layout of specimen

\subsection{Results of exposure test}

Based on the results of the exposure test, we evaluated the corrosion losses of the specimens and the appearance of their surfaces. Figure 5 shows the corrosion losses of the specimens exposed for a year. In P4 Lower Stage, where the largest amount of airborne salt was measured, the largest corrosion losses were observed. The values do not differ greatly by steel type. Figure 6 shows the corrosion losses of the specimens exposed for three years. The amounts differ by steel type compared with the specimens exposed for one year. Figure 7 shows the appearance of the specimens. In the most severely corrosive environment (P4 Lower Stage), the rust layer flakes away from the surface of the specimen. In relatively mild environment area (e.g. P10 Lower Stage), the rust layer shows no flaking, and thus corrosion loss is smaller than that in P4 Lower Stage. 


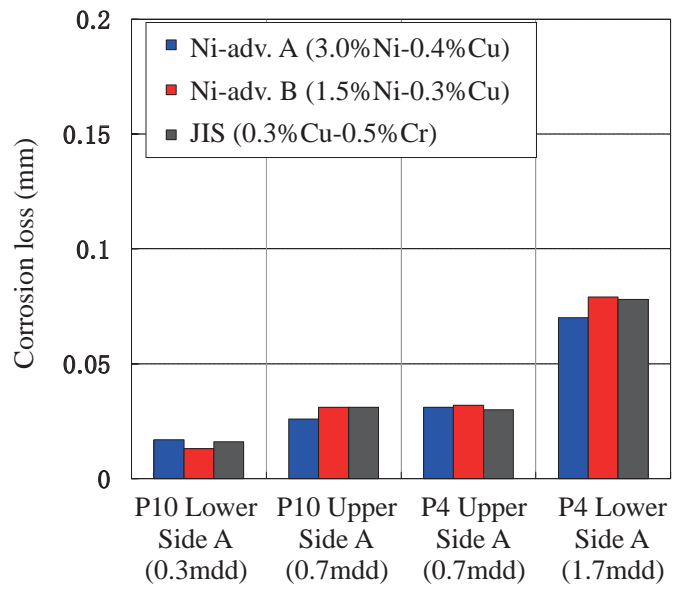

Fig. 5 Corrosion loss (1-year exposure)

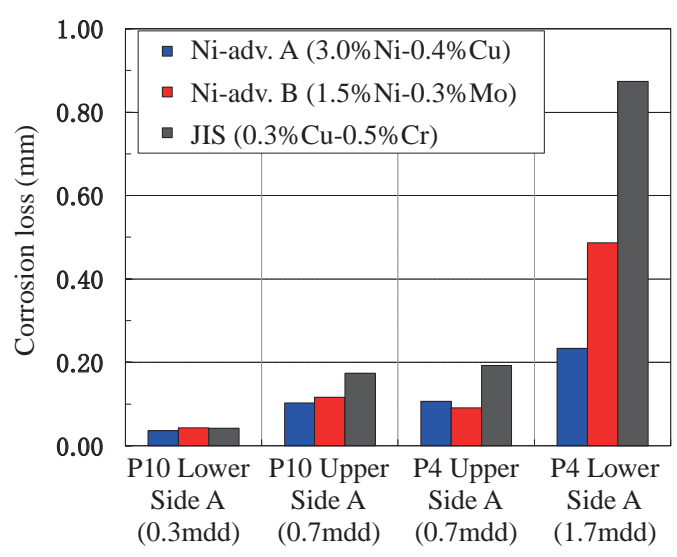

Fig. 6 Corrosion loss (3-year exposure)

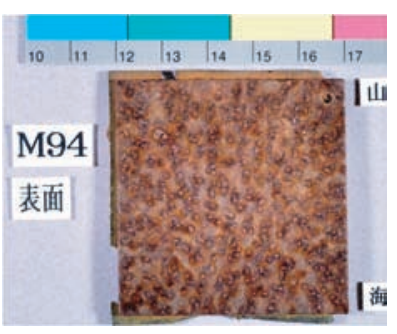

(a) P10 Lower stage,

Side B (web upper side)

(rust without flaking)

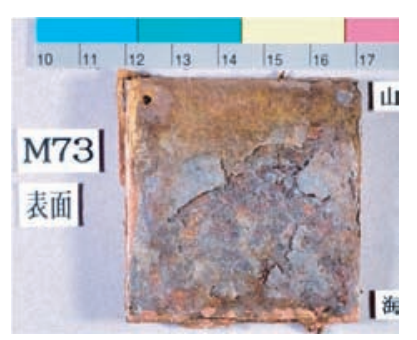

(b) P4 Lower stage

Side A (web lower side)

(rust with flaking) 3-year exposure

JIS weathering steel

\section{Fig. 7 Appearance of exposed specimens}

\subsection{Results of long-term corrosion loss prediction}

Using the corrosion loss values obtained from the results of the exposure test, we calculated the long-term corrosion losses of three types of weathering steel according to equation (1). Figure 8 shows the calculated longterm corrosion losses (hatched lines) and the corrosion losses obtained from the exposure test (plots) at the lower side (Side A) of the web at P10 Lower Stage. Using the new evaluation method, we can predict the corrosion loss appropriately, and it was found that $\mathrm{Ni}$-advanced weath-

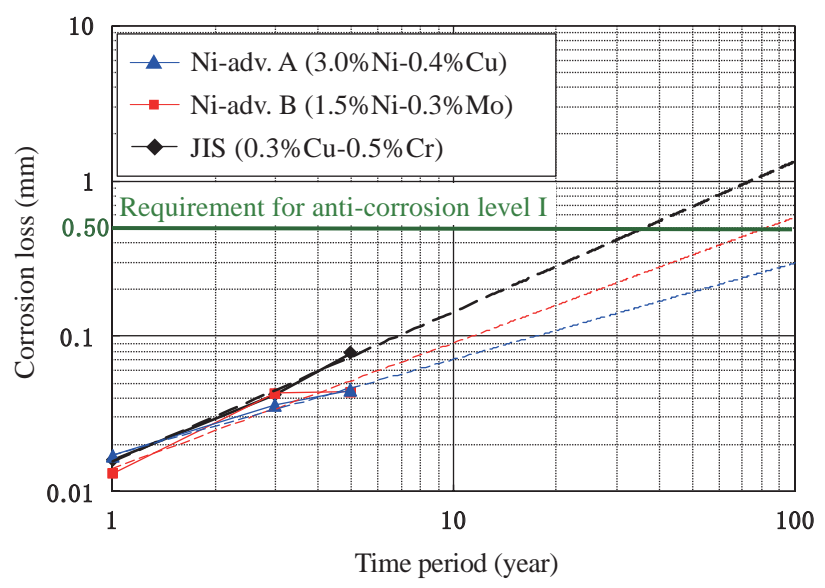

Fig. 8 Exposure test results and predicted corrosion loss values

ering steel type A $(3.0 \% \mathrm{Ni}-0.4 \% \mathrm{Cu}$ steel) satisfies the requirements of the environment at P10 Lower Stage. This new method enables more detailed evaluation of the applicability of Ni-advanced weathering steels than the existing method.

\section{Advantages of applying Bridge High-performance Steels to railway bridges}

\subsection{Bridge High-performance Steel}

Bridge High-performance Steel (BHS) was developed to increase bridge quality and reduce fabrication costs. It is produced through advanced thermal processing, which gives it enhanced weldability and formability as well as high yield stress [6]. Four types of steel were standardized (SBHS500, SBHS500W, SBHS700 and SBHS700W) under Japan Industrial Standards [7].

\subsection{Conditions of trial design}

To verify the advantages of applying BHS to railway bridges, we carried out a trial design of composite bridges. Table 3 shows the conditions of the design, which focused on simple girder bridges with standard spans of 40,60 and $80 \mathrm{~m}$. Figure 9 shows the cross section of an example bridge with a $60-\mathrm{m}$ span. The steel materials used for the trial design are shown in Table 4.

To verify the applicability and advantages of BHS application, we compared the results of trial design using SBHS500 with those obtained using SM570. The latter is the steel material with the highest level of strength among conventional structural steels. Here, SBHS700 was excluded from the comparison due to remaining problems with it, including its fatigue strength.

In the trial design, we verified elements of safety (failure, fatigue resistance and running safety) and serviceability (riding comfort) according to the design standard [1]. Here, assessment of durability was excluded under the precondition that corrosion protection and maintenance are appropriately carried out. 
Table 3 Conditions of trial design

\begin{tabular}{|c|c|}
\hline Type of structure & $\begin{array}{c}\text { Composite girder } \\
\text { (2 lines, double-box girder) }\end{array}$ \\
\hline Span & $40,60,80 \mathrm{~m}$ \\
\hline Axle load & $160 \mathrm{kN}($ Shinkansen $)$ \\
\hline Maximum velocity & $260 \mathrm{~km} / \mathrm{h}$ \\
\hline
\end{tabular}

Table 4 Steel material

\begin{tabular}{|c|c|c|}
\hline \multicolumn{2}{|c|}{ Material } & Yield strength \\
\hline SM570 & $\begin{array}{c}\text { High-strength steel } \\
\text { (JIS G 3106) }\end{array}$ & $450 \mathrm{~N} / \mathrm{mm}^{2}$ \\
\hline SBHS & $\begin{array}{c}\text { Bridge High-performance Steel } \\
\text { (JIS G 3140) }\end{array}$ & $500 \mathrm{~N} / \mathrm{mm}^{2}$ \\
\hline
\end{tabular}

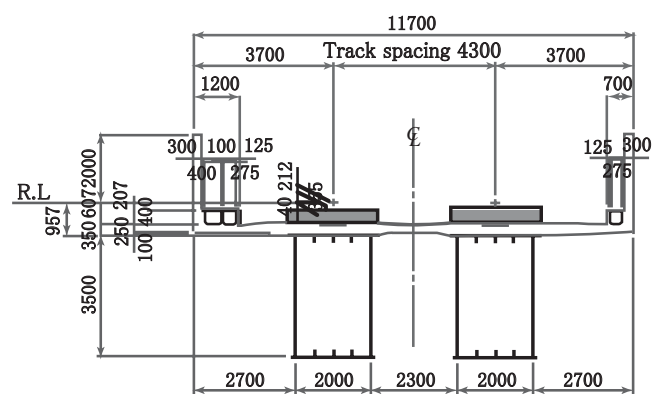

Fig. 9 Cross section of example bridge (60-m span)

\subsection{Results of trial design}

The results of performance verification on the example bridges are shown in Fig. 10. In the trial design, performance verification was carried out according to the following equation:

$$
\gamma_{i} \cdot I_{R d} / I_{I d} \leq 1.0
$$

where $\gamma_{i}$ : structure factor, $I_{\mathrm{Rd}}:$ design response value, and $I_{\mathrm{Id}}$ : design limit value. The verification results, which are plotted on the vertical axes of the graphs in Fig.10, are calculated according to the left-hand side of (2).

The verification results show the following:

(1) For verification of safety (failure), the verification result is the highest at the lower flange, and is a determinant of the cross section of the girders. By applying SBHS500, the cross section of the girders can be reduced, as shown in Table 5. Consequently, the total weight of the steel can be reduced by $5-7 \%$, as shown in Fig. 11. In terms of safety (failure), it is more advantageous to apply SBHS500.

(2) For verification of safety (fatigue resistance), the result is the highest at the welding connection at the lower end of the web. The result in the case of SBHS500 is higher than that in the case of SM570. This is because the design response value (here the stress of the member) is increased as a consequence of the reduced girder cross section by applying SBHS500. However, the verification results (fatigue damage) are less than 0.50, meaning that it is not a determinant of girder cross section.

(3) The verification results for safety (running safety) and serviceability (riding comfort) are also increased by applying SBHS500. This is because girder deflection increases as a consequence of the

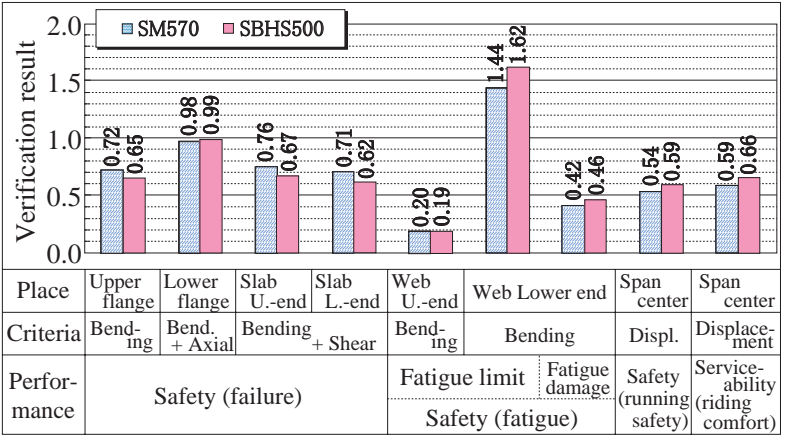

(a) 40-m span

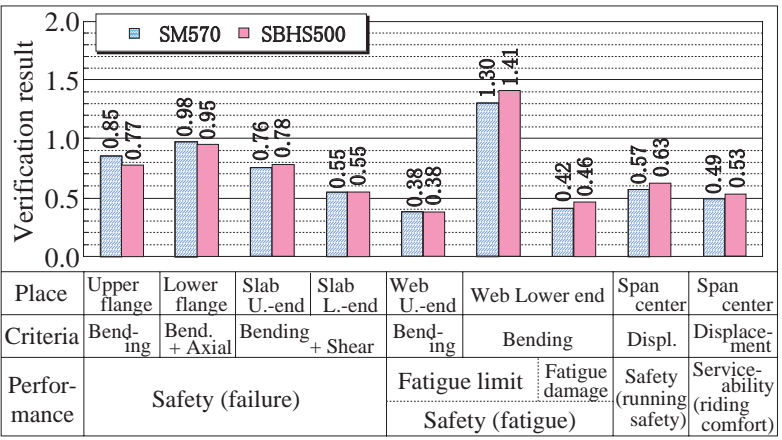

(b) 60-m span

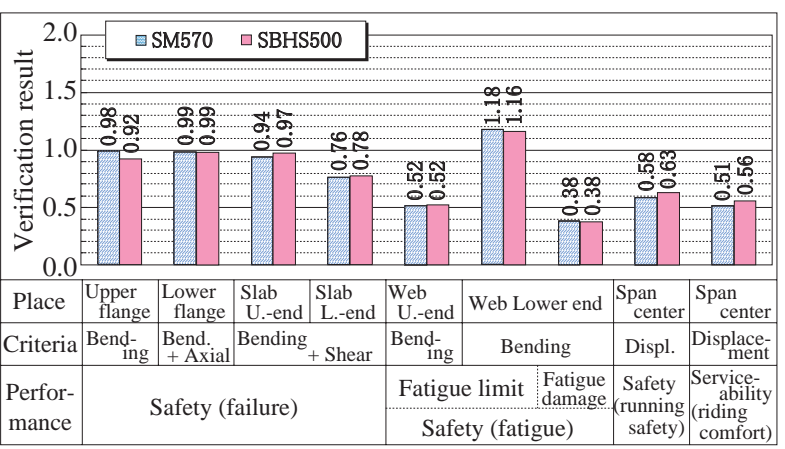

(c) 80-m span

Fig. 10 Results of performance verification

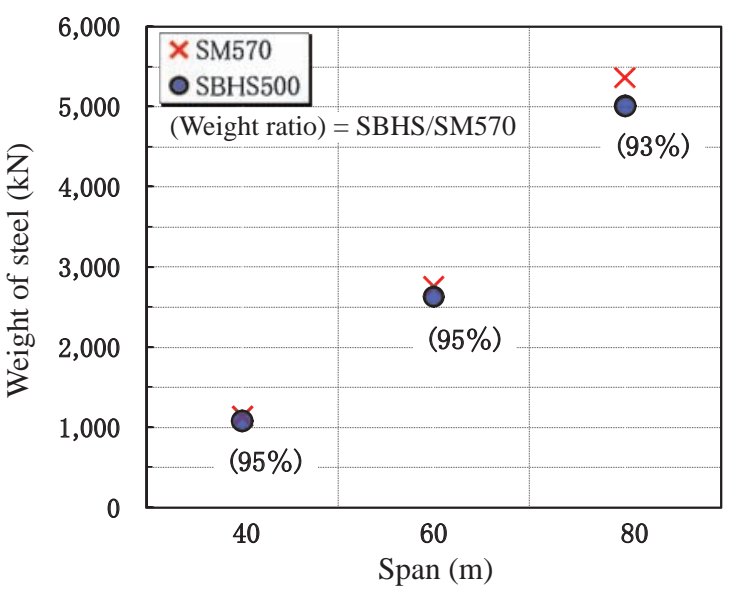

Fig. 11 Weight of steel

reduced girder cross section [8]. However, these verification results are also lower than the others, e.g. those for safety (failure). Accordingly, this 
Table 5 Dimensions of cross section and cross sectional area at the span center

\begin{tabular}{|c|c|c|c|c|c|c|c|c|}
\hline \multirow{2}{*}{\multicolumn{3}{|c|}{$\frac{\text { Span }}{\text { Material }}$}} & \multicolumn{2}{|c|}{$40 \mathrm{~m}$} & \multicolumn{2}{|c|}{$60 \mathrm{~m}$} & \multicolumn{2}{|c|}{$80 \mathrm{~m}$} \\
\hline & & & SM570 & SBHS500 & SM570 & SBHS500 & SM570 & SBHS500 \\
\hline \multirow{7}{*}{ 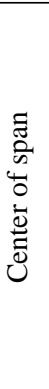 } & \multirow{6}{*}{ 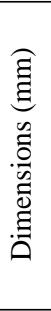 } & Slab & \multicolumn{2}{|c|}{$5,850 \times 250$} & \multicolumn{2}{|c|}{$5,850 \times 250$} & \multicolumn{2}{|c|}{$5,850 \times 250$} \\
\hline & & Upper flange & \multicolumn{2}{|c|}{$2,300 \times 15$} & \multicolumn{2}{|c|}{$2,300 \times 16$} & $2,300 \times 20$ & $2,300 \times 18$ \\
\hline & & Web & \multicolumn{2}{|c|}{$2,341 \times 9$} & \multicolumn{2}{|c|}{$3,500 \times 14$} & \multicolumn{2}{|c|}{$4,200 \times 17$} \\
\hline & & Web & \multicolumn{2}{|c|}{$2,200 \times 9$} & \multicolumn{2}{|c|}{$3,500 \times 14$} & \multicolumn{2}{|c|}{$4,200 \times 17$} \\
\hline & & Lower flange & $1,500 \times 26$ & $1,500 \times 22$ & $2,300 \times 23$ & $2,300 \times 19$ & $2,300 \times 38$ & $2,300 \times 32$ \\
\hline & & $\begin{array}{c}\text { Distance of web } \\
\text { (width of box girder) }\end{array}$ & \multicolumn{2}{|c|}{$\begin{array}{l}\text { Upper } 2,000 \\
\text { Lower } 1,200\end{array}$} & \multicolumn{2}{|c|}{$\begin{array}{l}\text { Upper 2,000 } \\
\text { Lower 2,000 }\end{array}$} & \multicolumn{2}{|c|}{$\begin{array}{l}\text { Upper 2,000 } \\
\text { Lower 2,000 }\end{array}$} \\
\hline & \multicolumn{2}{|c|}{$\begin{array}{l}\text { Resultant cross section of } \\
\text { steel girder }\left(\mathrm{mm}^{2}\right)\end{array}$} & 120,250 & 114,250 & 195,170 & 185,970 & 284,900 & 266,080 \\
\hline
\end{tabular}

is not a problem in actual use.

It was thus found that applying BHS can reduce the cross section of steel girders and lead to a reduction in the weight of the steel and in the material costs.

\subsection{Reduction of fabrication costs}

For the fabrication of conventional high-strength steel including SM570, preheating is required to prevent cold cracking of welded joints. This preheating increases fabrication costs, and is also costly in terms of the time taken for fabrication. On the other hand, BHS does not require preheating due to its low sensitivity to cracking. Accordingly, applying BHS allows the omission of preheating for the following weld joints, where preheating is required for SM570:

- Lower flanges

- Flange panels

- Web panels

- Diaphragms and transverse ribs

According to the trial design of the example bridge with an 80-m span, applying SBHS500 can reduce fabrication costs (excluding material costs) by $8 \%$ compared with applying SM570. Thus, applying BHS can contribute to economical bridge fabrication.

\section{Conclusions}

In this paper, we outlined applicability evaluation for $\mathrm{Ni}$-advanced weathering steels and the advantages of applying Bridge High-performance Steels to railway bridges.

As an method of applicability evaluation for unpainted weathering steels, we verified the effectiveness of the new method through exposure test and long-term corrosion loss prediction. We compared the results of exposure test and calculated long-term corrosion loss values. The results showed that the new method enables more detailed evaluation of applicability for $\mathrm{Ni}$-advanced weathering steels than the existing method.

To investigate the applicability of BHS and the advantages of its application to railway bridges, we carried out a trial design of composite girders. As a result, it was found that BHS application can reduce the weight of the steel by $5-7 \%$ due to its high strength characteristics, thereby reducing material costs. It can also reduce fabrication costs by $8 \%$ due to its enhanced weldability com- pared with the application of conventional steels.

In the revised design standard, Ni-advanced weathering steels and the new evaluation method involving longterm corrosion loss prediction of weathering steels are mentioned in Part I Chap. 5 "Materials" and Part II Chap. 5 "Assessment of durability." Bridge High-performance Steels are mentioned in Part I Chap. 5 "Materials."

\section{Acknowledgment}

This study was conducted as part of the Research for Railway Technical Standards project commissioned by the Ministry of Land, Infrastructure, Transport. The weathering steel exposure test was carried out in cooperation with the West Japan Railway Company and the Japan Iron and Steel Federation.

\section{References}

[1] Railway Technical Research Institute, "Design Standard for Railway Structures and Commentary (Steel and Composite Structures)," 2009 (in Japanese).

[2] Japanese Standard Association, JIS G 3114 "Hotrolled atmospheric corrosion resisting steels for welded structure," 2008.

[3] Railway Technical Research Institute, "Guideline for design and fabrication of unpainted steel railway bridges," 1994 (in Japanese).

[4] Miki, C., Ichikawa, A. et al., "Proposal for Weathering Alloy Index and Accelerated Corrosion Test Method to Select Weathering Steels," Doboku Gakkai Ronbunshuu, No. 738/I-64, pp. 271-281, 2003 (in Japanese).

[5] Japanese Society of Steel Construction, "Possibility and new technologies of weathering steel," 2006 (in Japanese).

[6] Miki, C., Ichikawa, A. et al. "Proposal of New High Performance Steels for Bridges (BHS500, BHS700)," Doboku Gakkai Ronbunshuu, No. 738/I-64, pp. 1-10, 2003 (in Japanese).

[7] Japanese Standard Association, JIS G 3140: 2008 "Higher Yield Strength Steel Plates for Bridges," 2008.

[8] Konishi, K., Takahashi, K. et al, "Application of High Strength Steel on Steel Bridge and Its Effects on Weight Reduction," Doboku Gakkai Ronbunshuu, No. 654 / I-64, pp. 91-103, 2003 (in Japanese). 